\title{
Cytoplasmic Nucleolin Expression in Chronic Lymphocytic Leukemia
}

\author{
Zeynep A. YEGIN, Mehmet S. PEPELER, Handan KAYHAN, \\ Hakan KOSEBIYIKOGLU, Sanem GOKCEN, Lale A. KAYNAR, Munci YAGCI
}

Gazi University School of Medicine, Department of Hematology, Ankara, TURKEY

Dear Editor,

Nucleolin (NCL), which is one of the most essential proteins in the nucleolus, has many physiological functions such as gene silencing, senescence and cell cycle regulation. Moreover, its significant role in a variety of cellular interactions including proliferative and apoptotic pathways is also demonstrated in several studies. ${ }^{1-3}$

Dysregulated accumulation of NCL mRNA and protein is found in a diverse range of cancers. Increased expression of NCL is reported to be associated with a poor prognosis in several tumors. ${ }^{2}$ Cytoplasmic NCL plays a distinct role in the stabilization of Bcl-2 and Bcl-xL mRNAs which may indicate a possible prognostic effect of NCL in the pathophysiology of lymphoproliferative disorders. ${ }^{4}$ Several reports have demonstrated the prognostic impact of NCL in hematological malignancies including acute myeloid leukemia (AML) and different types of lymphomas. ${ }^{4-9}$

This prospective study was planned to investigate the potential prognostic role of NCL in 58 newly diagnosed chronic lymphocytic leukemia (CLL) patients.

Cytoplasmic NCL was stained with Alexa Fluor-488 labelled anti-nucleolin antibody (Abcam, 364-5, Cat.no: ab154028) and Mouse monoclonal IgG1 (Abcam cat.no:ab171463) as a nega- tive control and analyzed by Beckman Coulter Flow cytometry (Navios) instrument with Kaluza Software. Although NCL is present in the nucleoplasm, cytoplasm and on the cell surface, cytoplasmic staining procedure of Beckman Coulter was applied to detect cytoplasmic NCL expression. Briefly, the protocol is as follows: $100 \mu \mathrm{l}$ of patient or control blood specimen with EDTA was incubated with intraprep 1 solution (Beckman Coulter) for $10 \mathrm{~min}$., washed and then incubated for $5 \mathrm{~min}$ with intraprep 2 solution (Beckman Coulter). After washing, the specimen was incubated with anti-nucleolin antibody for $20 \mathrm{~min}$, washed and analyzed with Beckman Coulter Navios. For evaluation, the quadrants were set according to the isotypic controls in Kaluza Software (Beckman Coulter). Cytoplasmic NCL levels were expressed as percentage values (Figure 1).

In statistical analysis, continuous variables were represented as median values and categorical variables as numbers and percentages. Continuous variables were compared using Mann Whitney U and Kruskal Wallis tests. Chi-square test was used for the comparison of categorical variables. Correlation analysis was performed using Pearson and Spearman tests. SPSS 16.0 (SPSS Inc, Chicago, IL, USA) programme was used for statistical analysis and $\mathrm{p}<0.05$ was considered as statistically significant. 


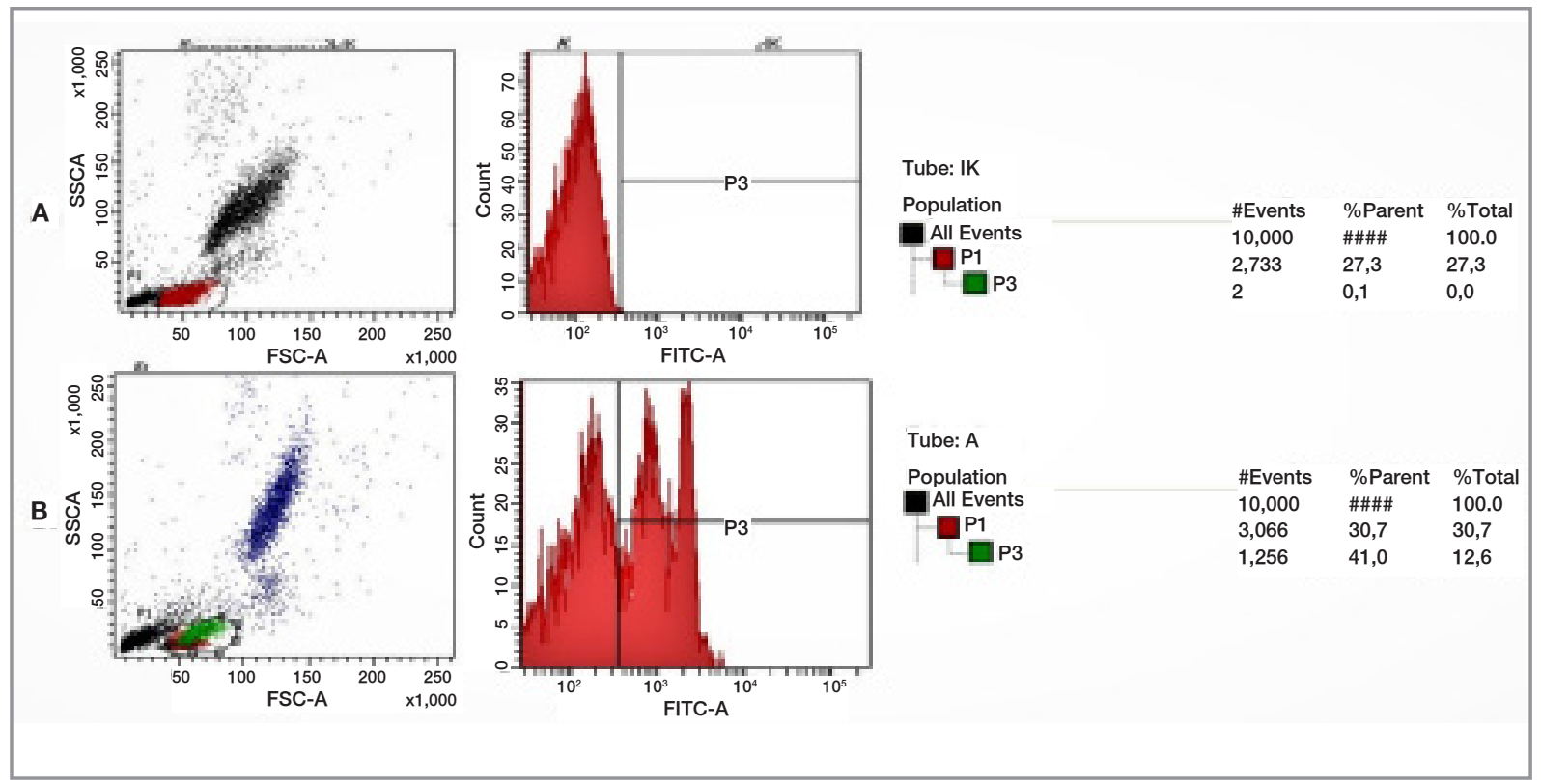

Figure 1. A serum sample which was stained for nucleolin and analyzed by Flow Cytometry (Navios model with Kaluza Software of Beckman Coulter). A. The sample was stained with Mouse monoclonal IgG1 as isotypic control (negative control), B. The same sample was stained with nucleolin to detect the cytoplasmic nucleolin expression. The quadrant was adjusted to the isotypic control to normalize nucleolin percentage.

Informed consent was taken from every patient after the explanation of the study protocol and procedure. The study was approved by the Turkish Ministry of Health Kecioren State Hospital Ethical Committee and in compatible with the principles of Helsinki declaration.

A total of 58 patients [median age: $69.5(42-91)$ years; male/female: 30/28] and 30 healthy volunteers were included in this prospective study. Patient characteristics are represented in Table 1. Nucleolin levels were not statistically different between the patient and control groups $(\mathrm{p}=0.09)$, nevertheless, were relatively higher in CLL patients compared to controls [7.95(0.1-99.8)\% vs $2.25(0.1-79.4) \%]$. A positive correlation was demonstrated between NCL expression and white blood cell count $(\mathrm{p}=0.044 ; \mathrm{r}=0.266)$. Nucleolin expressions were not statistically different between either CD38+ and CD38- patients ( $\mathrm{p}>0.05$ ) or ZAP70+ and ZAP70- patients ( $p>0.05)$. Nucleolin expressions were found to be similar among Modified Rai stages ( $p>0.05)$ and molecular risk groups ( $p>$ 0.05 ). As all patients were alive during the study period, survival analysis could not be performed.

Several reports have investigated the role of this multi-functional protein in hematological disorders, particularly in lymphomas. Wise et al identified NCL as a novel modulator of Fas signaling which is associated with Fas-resistance in B-cell lymphomas. Primary B cell lymphoma cells were shown to express higher levels of NCL compared to normal B lymphocytes. ${ }^{4}$ Nucleolin binds to cyclin D1 gene in mantle cell lymphoma (MCL) cells to activate cyclin D1 transcription. Nucleolin blockage leads to massive apoptosis in MCL cells. ${ }^{5}$ Nucleolin is overexpressed in diffuse large B cell lymphoma (DLBCL) cells and has an impact on survival via an interaction with TopIIA which blocks the TopIIA induced DNA damage and apoptosis. Therefore, it is suggested that the efficacy of TopIIA targeting agents might be enhanced by blocking NCL in DLBCL cells. ${ }^{6}$ High NCL mRNA expression was also associated with a poor survival in AML. ${ }^{7}$ Nucleolin overexpression associates with DNMT upregulation and shorter survival in AML patients. Nucleolin overexpression increases NF- $\kappa \beta$ phosphorylation and upregulates DNMT1 which is followed by DNA hypermethylation. Nucleolin may be used as a predictor in leukemia patients with relapse or unresponsiveness to DNA hypomethylating agents. ${ }^{8,9}$ 


\begin{tabular}{|c|c|}
\hline Age (years) [median(range)] & $69.5(42-91)$ \\
\hline \multicolumn{2}{|l|}{ Gender $[\mathrm{n}(\%)]$} \\
\hline Male & $30(51.7)$ \\
\hline Female & $28(48.3)$ \\
\hline Nucleolin (\%) [median (range)] & $7.95(0.1-99.8)$ \\
\hline White Blood Cell $(/ \mu \mathrm{L})$ [median (range)] & $\begin{array}{l}20425 \\
(3385-411900)\end{array}$ \\
\hline Lymphocyte (\%) [median (range)] & $69(6.5-93.5)$ \\
\hline Hemoglobin (g/dL) [median (range)] & $13.5(8.6-18.2)$ \\
\hline Platelet (/ $\mu \mathrm{L})$ [median (range)] & $\begin{array}{l}217150 \\
(46000-431000)\end{array}$ \\
\hline $\begin{array}{l}\text { Lactate dehydrogenase (mg/dL) } \\
\text { [median (range)] }\end{array}$ & $197(115-2095)$ \\
\hline $\begin{array}{l}\text { Beta-2 microglobulin (mg/L) } \\
\text { [median (range)] }\end{array}$ & $3.12(0.15-18.5)$ \\
\hline $\operatorname{lgG}(\mathrm{mg} / \mathrm{dL})$ [median (range)] & 1045 (613-2740) \\
\hline $\operatorname{lgA}(\mathrm{mg} / \mathrm{dL})[$ median (range)] & $137(13.6-500)$ \\
\hline $\operatorname{lgM}(\mathrm{mg} / \mathrm{dL})$ [median (range)] & $50.85(15.9-206)$ \\
\hline Kappa/Lambda & $0.92(0.22-6.2)$ \\
\hline \multicolumn{2}{|c|}{ Modified Rai classification $(n=50)[n(\%)]$} \\
\hline Low risk & $36(72)$ \\
\hline Intermediate risk & $12(24)$ \\
\hline High risk & $2(4)$ \\
\hline \multicolumn{2}{|l|}{ CD38 expression $(n=52)[n(\%)]$} \\
\hline Positive & $20(38.5)$ \\
\hline Negative & $32(61.5)$ \\
\hline \multicolumn{2}{|l|}{ ZAP70 expression $(n=47)[n(\%)]$} \\
\hline Positive & 19(40.4) \\
\hline Negative & $28(59.6)$ \\
\hline \multicolumn{2}{|c|}{ Molecular risk stratification (FISH) $[\mathrm{n}(\%)](\mathrm{n}=46)$} \\
\hline Negative & $23(50)$ \\
\hline Low risk & $8(17.4)$ \\
\hline Intermediate risk & $5(10.9)$ \\
\hline High risk & $10(21.7)$ \\
\hline \multicolumn{2}{|c|}{ Bone marrow infiltration pattern $[n(\%)](n=35)$} \\
\hline Diffuse & $11(31.4)$ \\
\hline Nodular & $16(45.7)$ \\
\hline Interstitial & $8(22.9)$ \\
\hline \multicolumn{2}{|c|}{$\begin{array}{l}\text { Abbreviations: FISH= Fluorescence in situ hybridization; } \\
\text { Ig=Immunoglubulin }\end{array}$} \\
\hline
\end{tabular}

In a study by Otake et al, the enhanced stability of Bcl 2 mRNA in CLL cells is shown to be related to the overexpression of cytoplasmic NCL in CLL cells. Nucleolin was overexpressed in the cytoplasm of 17 CLL patients, with an expression level which is 26-fold higher in CLL cells than normal B cells. In this study, NCL was overexpressed in CLL patients including those in early stages without prior therapy for CLL. Therefore, authors suggest that stabilization of Bcl 2 mRNA by NCL may be an early event in CLL pathogenesis rather than a feature of disease evolution or cytotoxic chemotherapy. In the same study, $65 \%$ of CLL patients demonstrated either downregulation or deletion of miR-15a and miR-16-1. Bcl2 upregulation in CLL cells may be due to increased Bcl2 mRNA stability by NCL up-regulation and/or increased Bcl2 mRNA translation via down-regulation of miR-15a and miR-16- $1 .{ }^{10}$ In the study by Otake et al, cytoplasmic NCL expression was analysed by polymerase chain reaction at transcriptional level. However, in our study, cytoplasmic protein product was measured by flow cytometric method. Statistical insignificance of higher NCL levels may be secondary to translational, post-translational and microRNA associated modifications as NCL undergoes extensive post-translational modification by phosphorylation, acetylation, methylation and ubiquitination. Small sample size may be another possible explanation.

As any significant impact of NCL on CLL course has not been demonstrated in this study, the role of NCL in CLL pathogenesis earns to be investigated in large populations to elucidate the interplay of apoptosis and NCL.

\section{REFERENCES}

1. Jia W, Yao Z, Zhao J et al. New perspectives of physiological and pathological functions of nucleolin (NCL). Life Sci 186: 1-10, 2017.

2. Xu X, Chen Z. Roles of nucleolin, focus on cancer and anticancer therapy. Saudi Med J 37: 1312-1318, 2016.

3. Berger CM, Gaume X, Bouvet P. The roles of nucleolin subcellular localization in cancer. Biochimie 113: 78-85, 2015.

4. Wise JF, Berkova Z, Mathur R et al. Nucleolin inhibits Fas ligand binding and suppresses Fas-mediated apoptosis in vivo via a surface nucleolin-Fas complex. Blood 121: 4729-4739, 2013.

5. Allinne J, Pichugin A, larovaia $O$ et al. Perinucleolar relocalization and nucleolin as crucial events in the transcriptional activation of key genes in mantle cell lymphoma. Blood 123: 2044-2053, 2014.

6. Jain N, Zhu H, Khashab T et al. Targeting nucleolin for better survival in diffuse large B-cell lymphoma. Leukemia 32: 663674, 2018.

7. Marcel V, Catez F, Berger CM et al. Expression profiling of ribosome biogenesis factors reveals nucleolin as a novel potential marker to predict outcome in AML patients. PLoS One 12(1): e0170160, 2017 
International Journal of Hematology and Oncology

8. Shen N, Yan F, Pang $\mathrm{J}$ et al. A nucleolin-DNMT1 regulatory axis in acute myeloid leukemogenesis. Oncotarget 5(14): 5494-509, 2014.

9. Gattoni-Celli S, Buckner CL, Lazarchick J et al. Overexpression of nucleolin in engrafted acute myelogenous leukemia cells. Am J Hematol 84: 535-538, 2009.

10. Otake $Y$, Soundararajan S, Sengupta TK et al. Overexpression of nucleolin in chronic lymphocytic leukemia cells induces stabilization of bcl2 mRNA. Blood 109: 3069-3075, 2007.

\section{Correspondence:}

Zeynep ARZU YEGIN, MD

Gazi Universitesi Tip Fakültesi

Hematoloji Anabilim Dali

06500, ANKARA / TURKEY

Tel: +90 3122025579

Fax: +903122236714

e-mail: zeyneparzuyegin@gmail.com 